Conclusions From the above results, the positive effect of essential elements to health examination values were not clear, little does the influence to the other non-essential elements. However, the damage from occupational non-essential elements exposure still needs to be concerned. Interaction to multi-elements also needs further research.

\section{POLYMORPHONUCLEAR LEUKOCYTES PHAGOCYTIC CAPACITY IN WORKERS OCCUPATIONALLY EXPOSED TO BENZENE}

'Luis Haro-García, ${ }^{2}$ Kendy Peggy Wek-Rodríguez, ${ }^{3}$ Carmina Jiménez-Ramírez, ${ }^{3}$ Cuauhtémoc Arturo Juárez-Pérez, ${ }^{3}$ Guadalupe Aguilar-Madrid, ${ }^{3}$ Alfonso Zárate-Amador, ${ }^{2}$ Oscar Rojas-Espinosa. 'Universidad Nacional Autónoma de México, FM Salud Pública, Ciudad de México, Mexico; ${ }^{2}$ Instituto Politécnico Nacional ENCB, Ciudad de México, Mexico; Instituto Mexicano Del Seguro Social, UIST, Ciudad de México, Mexico

\subsection{6/oemed-2014-102362.192}

Objectives To determine phagocytic capacity of PMN leukocytes in workers occupationally exposed to benzene.

Method Cross-sectional study that included 54 workers of a paint manufacture company in Mexico City; exposure to benzene was determined through S-phenylmercapturic acid (SPMA) presence in urine. The PMN phagocytic capacity analysis included three parameters: 1) nitro-blue tetrazolium (NBT) reduction, 2) hydrogen peroxide $\left(\mathrm{H}_{2} \mathrm{O}_{2}\right)$ production, and 3) cell adhesion (CAD)

Results In the whole of workers included in the study, NBT reduction $=0.419 \pm 0.075, \mathrm{H}_{2} \mathrm{O}_{2}$ production $=6.7 \pm 1.4 \mathrm{ng}$, and $\mathrm{CAD}=58.3 \pm 6.2 \mu \mathrm{g}$. SPMA was identified in all workers although 24 of them are not in occupationally exposure to organic solvents $(2.3 \pm 0.81 \mu \mathrm{mol} / \mathrm{mol} \mathrm{creatinine})$, while the remaining 30 handle these substances $(3.2 \pm 1.8, p=0.02)$. Among these exposure groups, there were not statistically differences in any of the parameters analysed. Although the simple regression analysis of these parameters with the concentration of SPMA identified in urine, a decrease was observed in NBT reduction $\left(\beta=-0.009, \mathrm{R}^{2}=0.01\right)$, in $\mathrm{H}_{2} \mathrm{O}_{2}$ production $(\beta=$ $\left.0.16, \mathrm{R}^{2}=0.02\right)$, and in $\operatorname{CAD}\left(\beta=-0.53, \mathrm{R}^{2}=0.01\right)$, none was statistically significant $(p \geq 0.05)$

Conclusions PMN phagocytic capacity in the workers studied seems to be intact. Attract attention the consistently decrease of the three parameters in relation to the concentration of SPMA identified in urine even when there was no statistical significance. Some limitations do not allow a more complete analysis, so it is encouraged to make further studies.

\section{EARLY PREDICTORS OF NOISE-INDUCED HEARING LOSS}

${ }^{1}$ Hanns Moshammer, ${ }^{1}$ Michael Kundi, ${ }^{1}$ Peter Wallner, ${ }^{2}$ Alois Herbst, ${ }^{2}$ Anton Feuerstein, ${ }^{1}$ Hans-Peter Hutter. ${ }^{1}$ Institute of Environmental Health, Medical University, Vienna, Austria; ${ }^{2}$ Voestalpine Steel Division, Linz, Austria

\subsection{6/oemed-2014-102362.193}

Objectives Noise-induced hearing loss (NIHL) is the most prevalent occupational disease in Austria and among the most frequent in many other countries. Because of the large interindividual variation in hearing loss after equal exposures it has long been assumed that some individuals are more vulnerable to NIHL. Earlier attempts to define predictors of NIHL before commencing occupational noise exposure have largely failed.
From a preventive point of view it would be essential to study predictive factors.

Method Between 1982 and 1989 overall 311 apprentices were included into a prospective study during their initial health screening visit. At this occasion a standardised noise exposure was applied (20 min $200-500 \mathrm{~Hz}, 100 \mathrm{dBA})$ and the temporal threshold shift (TTS) at $4 \mathrm{kHz}$ was determined during 2-10 min after exposure. Hearing loss was monitored at follow-up visits every 3-5 years. Follow-up was 13 years on average. Permanent threshold shift was predicted by noise years, frequency of wearing noise protectors, but also by the initial TTS at 4 $\mathrm{kHz}$.

Results In this longitudinal study again the importance of personal protective measures was documented, it was also established that individual susceptibility plays an important role. The TTS peak at $4 \mathrm{kHz}$ occurring independent of exposure frequency but especially after low-frequency exposure is a predictor of long-term hearing loss.

Conclusions Considering the importance of individual susceptibility current occupational limit values are likely not protective for everybody. This underlines the necessity of individualised screening programs and a strong commitment towards personal protection measures.

\section{OCCUPATIONAL EXPOSURE TO MINERAL DUST: EFFECTS OF ON LUNG FUNCTION IN A NINE-YEAR STUDY}

${ }^{1}$ Hanns Moshammer, ${ }^{2}$ Karl Hochgatterer, 'Daniela Haluza. 'Institute of Environmental Health, Medical University, Vienna, Austria; ${ }^{2}$ Centre of Occupational Health, Perg, Austria

\subsection{6/oemed-2014-102362.194}

Objectives Occupational mineral dust exposure is a well-known risk factor for numerous respiratory and systemic diseases. Stone work with high quartz exposure in quarries and in consecutive industries is a common situation in Austria. The aim of the present study employing a longitudinal design was to assess the influence of occupational dust exposure on lung function results. Further, the impact of implementation of stricter limit values for work-related contact with Quartz dust on lung function was evaluated.

Method Anthropometric data (age, gender, BMI), smoking behaviour, and lung function parameters (FVC, FEV1, MEF50) of 7204 medical examinations of 3229 female and male workers during the years 2002 to 2010 were analysed following Austrian standards for occupational medicine and ERS guidelines. Analysis of data was performed using models of linear regression.

Results Lung function parameters decreased with duration of occupational dust exposure and smoking. Occupational quartz exposure negatively influenced lung function parameters (FVC $173.98 \mathrm{ml}$, FEV1 -127.94 ml, MEF50 -200.44 ml/s; all p < 0.001). Implementation of stricter Austrian occupational limit values for dust exposure resulted in a highly significant deceleration of annual respiratory decrease.

Conclusions The decrease of lung function is correlated with individual smoking habits and the duration of occupational dust exposure. Smoking cessation is especially recommended to workers exposed to Quartz dust to reduce the risk of increase of poor lung function. Adaptation of current limit values towards stricter limit values could decrease chronic occupational damage of the respiratory system. 